\title{
Ni Nano Level Thin Film Formation on p-GaN and Improvement of Electrical Properties by Hydrogen Release Enhancement
}

\author{
Aiman bin Mohd HALIL*, Keisuke TSUCHIDA*, Masakatsu MAEDA** and Yasuo TAKAHASHI***
}

(Received January 30, 2015)

\begin{abstract}
$\mathrm{Ni}$ thin film $(\sim 20 \mathrm{~nm})$ was uniformly formed on p-GaN substrates by radio frequency magnetron sputter deposition method. In order to improve the conductivity and electrical contact properties of Mg-doped p-GaN, the enhancement of $\mathrm{H}$ release from Mgdoped p-GaN was attempted by applying current flow through the substrates during low temperature annealing at $573 \mathrm{~K}$ and $673 \mathrm{~K}$. The microstructure and electrical properties after the annealing were then analyzed by transmission electron microscopy observation, direct current conduction tests and Hall effect measurement tests. The results reveal that no reactions occur at the interface between deposited $\mathrm{Ni}$ film and p-GaN substrate during annealing at $573 \mathrm{~K}$ for $3600 \mathrm{~s}$. The electrical conductivity of p-GaN shows higher improvement by applying current flow during annealing at $573 \mathrm{~K}$ and $673 \mathrm{~K}$, compared to annealing without the current flow. To investigate the effect of applying current flow during annealing, the current values of the samples during annealing with and without applying current flow were measured and they were compared. The mechanism of $\mathrm{H}$ release from $\mathrm{p}$-GaN by applying current flow during annealing were discussed.
\end{abstract}

Key Words: p-type Gallium Nitride, Ni Thin Film, Hydrogen Release, Annealing, Current Flow, Microstructures, Electrical Properties

\section{Introduction}

Silicon ( $\mathrm{Si}$ ) is still now used mainly as power electronic devices. But, it is important to seek for better alternative materials for use in the next-generation power electronic devices due to the physical limitation of silicon. Gallium nitride $(\mathrm{GaN})$ is one of the most promising candidates. Also, GaN has an advantage as a high frequency communication element. GaN-based power electronic devices promises higher energy efficiency devices with capability of handling higher power and longer service life ${ }^{1), 2}$, compared with silicon devices. However, in spite of having a significant development in the crystal growth ${ }^{3), 4)}$ and device processing technology of light emitting diodes (LED) and laser diodes (LDs) ${ }^{5}$, the application of $\mathrm{GaN}$ semiconductor to power electronic devices is still far from real.

One of the main problem is the difficulties in formation of low resistance ohmic contact to p-type GaN. GaN has to be connected with metallic materials to form an electric circuit. However, due to the very deep valance band edge for p-type GaN (7.50 $\mathrm{eV}$ under the vacuum level), there is no pure metallic element which can directly form ohmic contact with p-type GaN. Without the formation of ohmic contact, the interference of carrier will occur at the contact interface, which generates Joule heat and deteriorates the energy efficiency and the reliability of the devices. Hence, to form an efficient and reliable power electronic device, a clear understanding on formation of low resistance ohmic contact between semiconductors and metallic materials by reducing the Schottky barrier (SB) height and/or width at the contact interface is needed.

The other important problem in realizing GaN-based power electronic devices are related to the low electrical conductivity of $\mathrm{p}$-GaN. The only effective p-type dopant known for $\mathrm{p}$-GaN is magnesium $(\mathrm{Mg})$. Although some decent annealing methods were developed ${ }^{6,7)}$ after the breakthrough discovery of $\mathrm{Mg}$ activation by electron beam irradiation ${ }^{8)}$, new developments of improvement methods for p-type GaN conductivity have not been accomplished. It is reported that only approximately one percent of doped magnesium atoms are activated during $\mathrm{Mg}$ activation $^{9), 10)}$. This is due to the presence of hydrogen $(\mathrm{H})$ within the Mg-doped $\mathrm{p}-\mathrm{GaN}$, incorporated during growth ${ }^{11)}$. $\mathrm{H}$ is known to electrically passivate the acceptors ${ }^{12)}$. This passivation is attributed to the formations of neutral $\mathrm{Mg}-\mathrm{H}$ complexes where $\mathrm{H}$ is bonded interstitially to a neighboring nitrogen atom ${ }^{13)-15)}$. Furthermore, in order to achieve p-type conductivity, postgrowth activation of $\mathrm{Mg}$ by thermal annealing, which releases $\mathrm{H}$ from $\mathrm{GaN}$, is necessary ${ }^{6}$. The thermal annealing is believed to releases $\mathrm{H}$ from $\mathrm{GaN}$ but not so effective. The high annealing temperature (973 K) was required to achieve p-type conductivity, but high

* Division of Materials and Manufacturing Science, Graduate School of Engineering, Osaka University (2-1 Yamadaoka, Suita, Osaka, 565-0871 Japan)

* * Department of Mechanical Engineering, College of Industrial Technology, Nihon University (1-2-1 Izumicho, Narashino, Chiba, 275-8575 Japan) *** Joining and Welding Research Institute, Osaka University (11-1 Mihogaoka, Suita, Osaka, 565-0047 Japan) 
temperature annealing damages $\mathrm{GaN}$ device, because GaN is decomposed and $\mathrm{N}$ vacancy concentration increases in $\mathrm{GaN}$, i.e., this phenomenon lowers the p-type conductivity of $\mathrm{GaN}^{16}$. Thus, it is important to understand and improve the processes of $\mathrm{H}$ release from $\mathrm{p}-\mathrm{GaN}$ under lower temperature conditions. By enhancing the $\mathrm{H}$ release from $\mathrm{p}-\mathrm{GaN}$, the electrical properties of p-GaN contact interface also can be improved. The higher carrier (accepter) concentration achieved by enhancing the $\mathrm{H}$ release from $\mathrm{p}-\mathrm{GaN}$ will also reduce the width of the SB formed at the contact interface. By thinning the SB width, the probability of carrier to tunneling through the SB can be increased, resulting in improvement of the electrical properties of the p-GaN contact.

In the present study, in order to improve the conductivity and electrical contact properties of Mg-doped $\mathrm{p}-\mathrm{GaN}$, the enhancement of $\mathrm{H}$ release from $\mathrm{Mg}$-doped $\mathrm{p}-\mathrm{GaN}$ under temperatures much lower than $973 \mathrm{~K}$ is attempted by applying current flow through the $\mathrm{p}-\mathrm{GaN}$ substrates during low temperatures annealing (573 $\mathrm{K}$ and $673 \mathrm{~K}$ ). In that stage, pure $\mathrm{Ni}$ is used as an electric pad (contact) film because $\mathrm{Ni}$ does not react on nitrogen in $\mathrm{GaN}$ and has a work function of $5.15 \mathrm{eV}$. The microstructures and electrical contact properties after annealing were analyzed by transmission electron microscopy (TEM), direct current (DC) conduction tests and Hall effect measurement test. Finally, mechanisms of $\mathrm{H}$ release from $\mathrm{Mg}$-doped $\mathrm{p}-\mathrm{GaN}$ during annealing with current flow are discussed, based on the results of the change in current values of $\mathrm{p}-\mathrm{GaN} / \mathrm{Ni}$ contact with time.

\section{Experimental procedure}

Substrates used in the present study were $2.0-\mu \mathrm{m}$-thick p-type GaN epitaxially grown on a 330- $\mu \mathrm{m}$-thick sapphire (0001) wafer with undoped GaN buffer layer. The thickness of undoped GaN was $2.3 \mu \mathrm{m}$. The surface orientation and carrier concentration of the substrate were $(0001)$ Ga-face and $3 \times 10^{17} \mathrm{~cm}^{-3}$, respectively. The sizes of all substrates were $4.0-\mathrm{mm}$-square. The electric pad (contact) areas were obtained by using 1.0-mm-wide Al masking ribbons. Before the sputter deposition process, the substrates were cleaned with acetone applying ultrasonic vibration. After that, the substrates were fixed on the deposition plate designed in a radiofrequency magnetron sputtering deposition apparatus. Ni (99.99 mass \%) plates were used as a target material, i.e., Ni atoms were sputter-deposited to form a thin contact film on $\mathrm{p}-\mathrm{GaN}$.

Before sputter deposition Ni thin film on the electric pad area, the surfaces of Ni target and substrates ( $\mathrm{p}-\mathrm{GaN}$ with pad areas) were sputter-cleaned to remove native oxide layer. The sputter cleaning was carried out under 20 and $0.8 \mathrm{~Pa}$ of high-purity Ar (99.9999 volume \%), respectively, under a radio-frequency power of $200 \mathrm{~W}$. The sputter cleaning time was $300 \mathrm{~s}$. The sputter deposition of Ni thin film was performed under 20 Pa high-purity

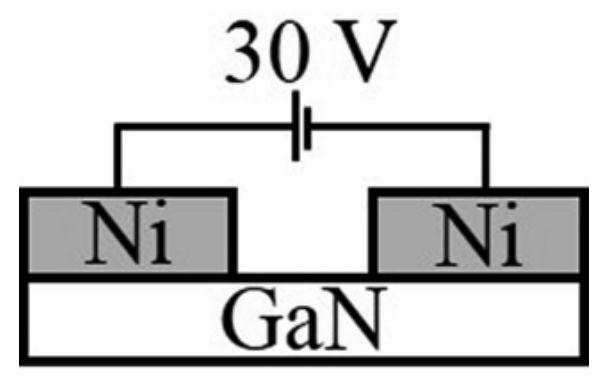

Fig. 1 Schematic illustration of the method of applying current flow through the substrates during annealing.

$\operatorname{Ar}(99.9999$ volume \%) under a radio-frequency power of $200 \mathrm{~W}$ for $1800 \mathrm{~s}$.

Some of the deposited samples were then subjected to annealing at $573 \mathrm{~K}$ and $673 \mathrm{~K}$ under $0.1 \mathrm{MPa}$ of nitrogen ambient for $3600 \mathrm{~s}$. During the annealing, some of the samples were subjected to current flow under the condition of DC $30 \mathrm{~V}$. The schematic illustration of this method are shown in Fig. 1 .

The microstructure and electrical properties of the samples were then analyzed by TEM observation and DC conduction tests at room temperature and Hall effect measurement test using the van der Pauw method at room temperature. Finally, current values of the $\mathrm{p}-\mathrm{GaN} / \mathrm{Ni}$ contact dependence on time during annealing at $673 \mathrm{~K}$ while subjected to current flow under the condition of $10 \mathrm{~V}$ were observed. The current values $I$ and $I_{0}$ were measured under condition of $1.0 \mathrm{~V}$.

\section{Results and discussion}

Fig. 2 shows the TEM microstructure of the $\mathrm{p}-\mathrm{GaN} / \mathrm{Ni}$ contact interface after annealing at $573 \mathrm{~K}$ for $3600 \mathrm{~s}$. As seen in the bright-field image, Fig. 2 (a), a thin layer of Ni film is observed on p-GaN substrate. The thickness is approximately $20 \mathrm{~nm}$ and the Ni film is very uniform. Next, the electron diffraction pattern from this area was taken. The result is shown in Fig. 2 (b). The dashed-circle can be estimated as a Debye-Scherrer ring of $\mathrm{Ni}$ (111) if the Ni polycrystals is formed. However, no rings are observed and the diffraction pattern consists of only net pattern of $\mathrm{GaN}$. This result indicates that after the annealing at $573 \mathrm{~K}$ for $3600 \mathrm{~s}$, the crystallization of Ni film still does not occur or the Ni film is in a very early stage of crystallization. Fig. 2 (c) shows the dark-field image taken using the diffraction of the circle (c) in Fig. 2 (b) which must be including diffractions of GaN (0002) and Ni (111). In the image of Fig. 2 (b), GaN and Ni film appears darkly and no interfaces appear between them. Therefore, it is confirmed that there are no compound formations at the interface, i.e., no reactions occur between $\mathrm{GaN}$ and $\mathrm{Ni}$ during the annealing at $573 \mathrm{~K}$. 

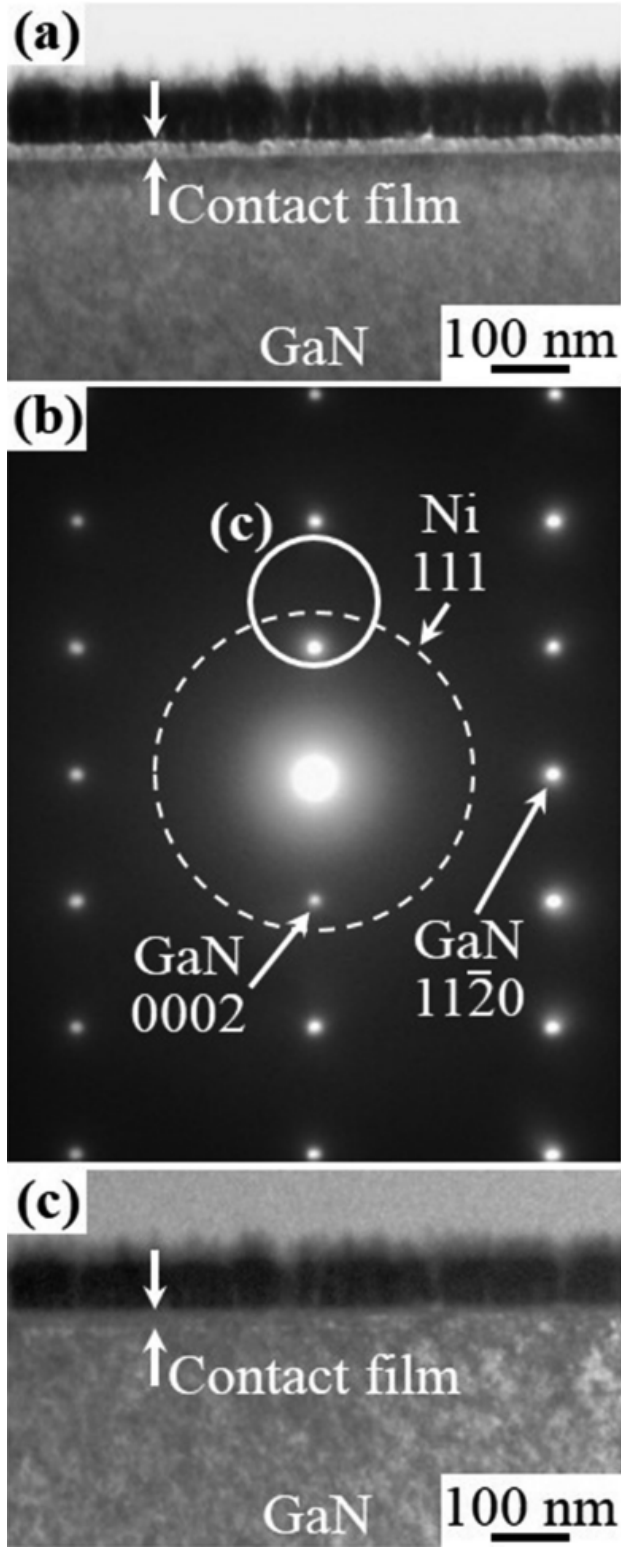

Fig. 2 Microstructure of $\mathrm{p}-\mathrm{GaN} / \mathrm{Ni}$ contact after annealing at $573 \mathrm{~K}$ for 3600 s. (a) bright-field image, (b) selected area electron diffraction pattern of the area shown in (a), (c) dark-field image of the area shown in (a) using diffraction of circle (c) in (b).

If some reaction occurs at the interface between $\mathrm{GaN}$ and $\mathrm{Ni}$ film, Ni-Ga intermetallic compounds will be formed at the interface. Compared with $\mathrm{Ni}$, these intermetallic compounds have lower values of work functions. Thus, the formation of these compounds at the interface will increase the SB height and deteriorate the electrical properties of the contact. This reaction will also introduce unstable $\mathrm{N}$ atoms within $\mathrm{p}-\mathrm{GaN}$ substrates, which consequently diffuse to the interface of $\mathrm{p}-\mathrm{GaN}$ and $\mathrm{Ni}$ film and form voids. The formation of voids at the interface decreases the area of contact interface and deteriorates the

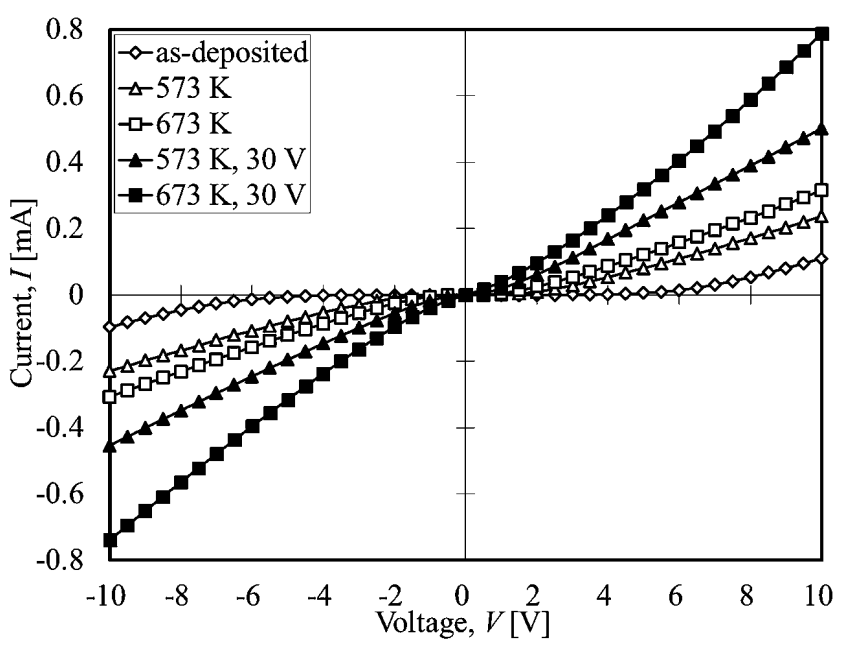

Fig. 3 Electrical conduction profiles of the samples.

electrical properties of the p-GaN/Ni contact. As seen in Fig. 2 (c), no reaction layers exist at the interface. So, the reaction of $\mathrm{Ni}-\mathrm{Ga}$ under the annealing condition of $573 \mathrm{~K}$ for $3600 \mathrm{~s}$ can be negligible, i.e., the deterioration of electrical properties of the contact have been avoided by annealing at low temperature.

Fig. 3 shows the electrical conduction profile ( $I-V$ curves) of the samples, where $I$ is the current and $V$ is the voltage between two adjacent electric pads. The electrical conduction profiles of the sample annealed at $573 \mathrm{~K}$ and $673 \mathrm{~K}$ for $3600 \mathrm{~s}$ without current flow (marks of $\triangle$ and $\square$ ) show some improvement compared to the electrical conduction profile of the as-deposited sample (marks of $\diamond$ ). Due to no structural change during the annealing as shows by the TEM observation, this electrical conduction improvement can be attribute to the enhancement of $\mathrm{H}$ release from $\mathrm{p}-\mathrm{GaN}$ by the annealing at $573 \mathrm{~K}$ and $673 \mathrm{~K}$. The carrier (accepter) concentration is increased by the $\mathrm{H}$ release and consequently reduce the $\mathrm{SB}$ width at the contact interface. As a result, $I-V$ properties of the contacts are improved.

During the growth process of $\mathrm{GaN}, \mathrm{H}$ is dissolved into $\mathrm{GaN}$ exceeding the saturated point due to the very high concentration of $\mathrm{H}$ in the process ambient. $\mathrm{H}$ formed neutral $\mathrm{Mg}-\mathrm{H}$ complexes within $\mathrm{p}-\mathrm{GaN}$, thus cannot be released without annealing. Therefore, the postgrowth activation of $\mathrm{Mg}$ by annealing at $973 \mathrm{~K}$, which releases $\mathrm{H}$ from $\mathrm{GaN}$ is necessary. However, residual $\mathrm{H}$ still presence within $\mathrm{p}-\mathrm{GaN}$ even after the postgrowth annealing process. The $\mathrm{H}$ release by annealing at $573 \mathrm{~K}$ and 673 $\mathrm{K}$ in present study indicates most of the $\mathrm{H}$ incorporated during growth process of GaN still exists even after the postgrowth annealing process at $973 \mathrm{~K}$. The $\mathrm{H}$ within $\mathrm{p}-\mathrm{GaN}$ must be still in supersaturated state because $\mathrm{H}$ must still combine with $\mathrm{Mg}$, thus can be released by annealing even at low temperatures ( $573 \mathrm{~K}$ and 


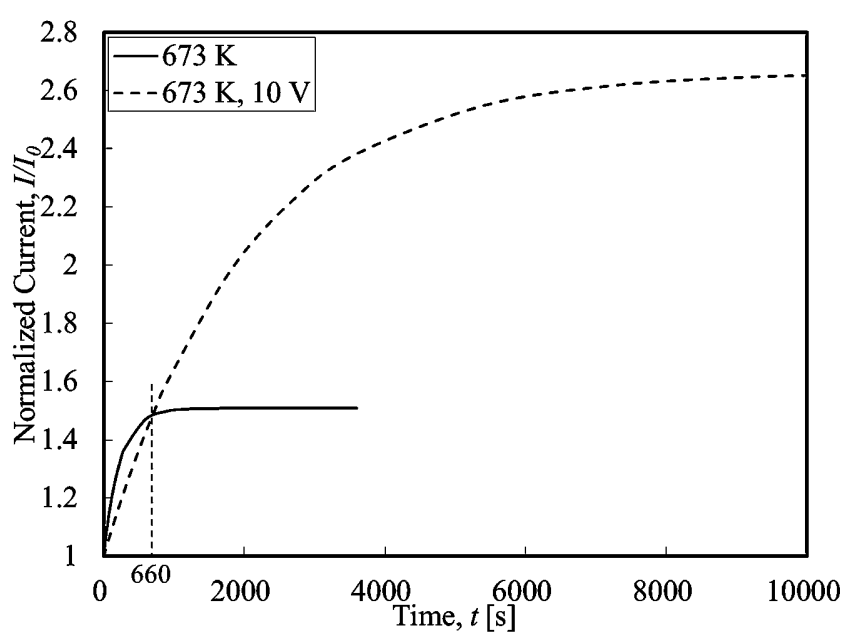

Fig. 4 Normalized values of current $(V=1.0 \mathrm{~V})$ of the samples dependence on time (curve-fitted to experimental data) during annealing at $673 \mathrm{~K}$ while subjected to current flow under the condition of $10 \mathrm{~V}$. (I: Current value for $V=1.0 \mathrm{~V}, I_{0}$ : Current value for $V=1.0 \mathrm{~V}$ at $t=0 \mathrm{~s})$.

$673 \mathrm{~K})$.

By applying current flow through the substrates during annealing at $573 \mathrm{~K}$ and $673 \mathrm{~K}$ for $3600 \mathrm{~s}$ (marks of $\boldsymbol{\Delta}$ and

$\square)$, some further improvements of electrical conduction are achieved, as can be seen in Fig. 3. These further improvements of electrical properties of the contacts imply that significant amount of $\mathrm{H}$ within $\mathrm{p}-\mathrm{GaN}$ has been released by applying current flow during annealing at $573 \mathrm{~K}$ and $673 \mathrm{~K}$, resulting in improving $I-V$ properties of the contacts. The amount of $\mathrm{H}$ released from $\mathrm{p}-\mathrm{GaN}$ subjected to current flow during annealing must be much higher compared to without the current flow.

As seen in Fig. 3, the samples annealed at $673 \mathrm{~K}$ show greater improvement in $I-V$ properties compared to anneal at $573 \mathrm{~K}$. Therefore, to understand the mechanism of $\mathrm{H}$ release by current flow during annealing, the change of current values of the $\mathrm{p}-\mathrm{GaN} /$ $\mathrm{Ni}$ contact during annealing at $673 \mathrm{~K}$ while subjected to current flow under the condition of $10 \mathrm{~V}$ were observed. When the current was measured, the voltage was reduced from $10 \mathrm{~V}$ to $1.0 \mathrm{~V}$. Fig. 4 shows the normalized values of current which change with time, for the samples subjected to annealing at $673 \mathrm{~K}$ with and without the current flow. Two curves (dotted and solid curves) in Fig. 4 were obtained by the least square fitting methods of log-log plots from the measured values.

The results reveal that at the early stage up to $660 \mathrm{~s}$ into the annealing, the sample subjected to only annealing (solid curve) show greater increase of current values compared to sample subjected to current flow during annealing (dotted curve). However, after $660 \mathrm{~s}$ into the annealing, the solid curve starts to

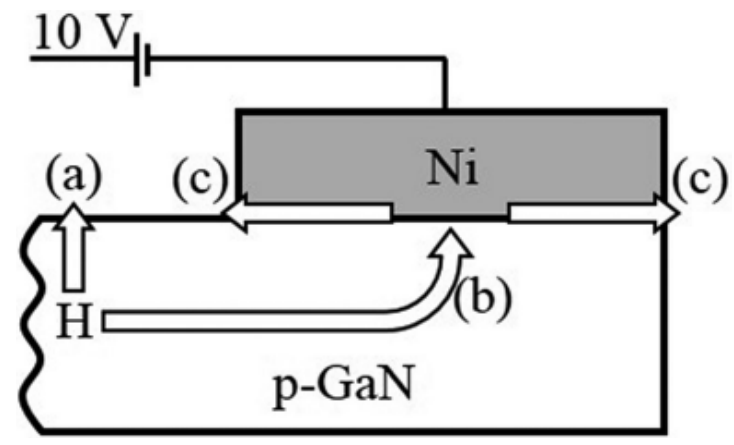

Fig. 5 Schematic illustration of the routes of $\mathrm{H}$ release mechanism from p-GaN by applying current flow during annealing: (a) $\mathrm{H}$ released through exposed $\mathrm{p}-\mathrm{GaN}$ surface, (b) $\mathrm{H}$ within $\mathrm{p}-\mathrm{GaN}$ moved near the interface by applied current flow, (c) $\mathrm{H}$ diffuses along the interface to the exposed surface and released from $\mathrm{p}-\mathrm{GaN}$.

saturate. In the other hand, the dotted curve keeps increasing until $8000 \mathrm{~s}$ into the annealing before starts to saturate.

These results show that the increasing behavior of current values of the samples during annealing, i.e., the enhancement of $\mathrm{H}$ release from $\mathrm{p}-\mathrm{GaN}$ is significantly affected by applying current flow. Fig. 5 shows the schematic illustration of the routes of $\mathrm{H}$ release mechanisms from $\mathrm{p}-\mathrm{GaN}$ by applying current flow during annealing. The arrow mark of (a) illustrates the $\mathrm{H}$ released through exposed $\mathrm{p}-\mathrm{GaN}$ surface, which occurs during annealing with or without the current flow applied. The driving force for the $\mathrm{H}$ release in this route is the supersaturated state of $\mathrm{H}$ within $\mathrm{p}-\mathrm{GaN}$. As reveal in electrical conduction test, the $I-V$ properties of the contacts can be improve by annealing even at low temperatures, i.e., $\mathrm{H}$ within $\mathrm{p}-\mathrm{GaN}$ can be released by annealing even at low temperatures ( $573 \mathrm{~K}$ and $673 \mathrm{~K}$ ). However, amount of $\mathrm{H}$ released by this mechanism is dependent to the $\mathrm{H}$ concentration within $\mathrm{p}-\mathrm{GaN}$. When the $\mathrm{H}$ concentration within $\mathrm{p}-\mathrm{GaN}$ decrease and reach a saturated point of $\mathrm{H}$ in $\mathrm{GaN}$, no more $\mathrm{H}$ is released. This mechanism can be detectable from the increase of current values of sample subjected to only annealing as shown in Fig. 4 (solid curve). After annealing for $660 \mathrm{~s}$ at $673 \mathrm{~K}$, no more increase of current value is achieved, i.e., the $\mathrm{H}$ concentration within $\mathrm{p}-\mathrm{GaN}$ have reach a saturated point and no more $\mathrm{H}$ is released. The saturated point must still be much higher than the equilibrium solubility.

The arrows marks as (b) and (c) in Fig. 5 illustrate the routes of $\mathrm{H}$ release from $\mathrm{p}-\mathrm{GaN}$ by applying current flow during annealing. By increasing the temperature of the substrates, the bond of neutral $\mathrm{Mg}-\mathrm{H}$ complexes within $\mathrm{p}-\mathrm{GaN}$ brake, and $\mathrm{H}$ gain enough mobility to be effected by the current flow. The $\mathrm{H}$ form $\mathrm{H}$ ions which then is moved near the interface between $\mathrm{p}-\mathrm{GaN}$ and $\mathrm{Ni}$ film by the applied current flow, as shown as arrow (b) in Fig. 5. 
However by moving $\mathrm{H}$ ions near the interface by applying current flow, the $\mathrm{H}$ concentration of other area of $\mathrm{p}-\mathrm{GaN}$ decreases. Thus, the $\mathrm{H}$ release by mechanism (a) must be slowed. The interaction between these two mechanisms can be observed by comparing the results of both samples in Fig. 4. At the early stage of the annealing $(0 \mathrm{~s}$ to $660 \mathrm{~s})$, the increase of current values for sample subjected to current flow during annealing (dotted curve) is slower compared sample subjected to only annealing (solid curve). This is due to the longer routes for $\mathrm{H}$ release through (b) and (c), compared to through route (a).

After $\mathrm{H}$ ions are moved near to the interface between $\mathrm{p}-\mathrm{GaN}$ and $\mathrm{Ni}$ film by applied current flow during annealing, $\mathrm{H}$ ions diffuse along the interface to the expose surface and goes out of $\mathrm{p}-\mathrm{GaN}$. H cannot be released through Ni film because Ni does not contain $\mathrm{H}$ at all. The route of this mechanism is illustrated by arrow (c) in Fig. 5. H concentration adjacent to the interface is constantly higher than that of the area near to exposed surface due to mechanism (b). Therefore, $\mathrm{H}$ release by mechanism (c) will keep occurring until the $\mathrm{H}$ concentration near the interface is reduced and reach a lower saturated point of $\mathrm{H}$ in GaN. The interaction between mechanisms (b) and (c) can be observed from the increase of current values of sample subjected to current flow during annealing as shown in Fig. 4 (dotted curve). The current value keep increasing until $8000 \mathrm{~s}$ into the annealing, which when the value start to saturate. At this stage, the $\mathrm{H}$ concentration within $\mathrm{p}-\mathrm{GaN}$ is reduced to the point no more $\mathrm{H}$ can be released even by applying current flow during annealing. These result also indicate that the improvement of electrical properties of the contacts achieved by applying current flow through the substrates during annealing at $573 \mathrm{~K}$ and $673 \mathrm{~K}$ (marks of $\boldsymbol{\Delta}$ and $\boldsymbol{\square}$ ) for 3600 s shown in Fig. 3 can be further improve by prolonging the annealing times.

In the present study, the mechanisms of $\mathrm{H}$ release by current flow during annealing at the cathode electrode have been discussed. However, $\mathrm{H}$ ions within $\mathrm{p}-\mathrm{GaN}$ can exist as $\mathrm{H}^{+}$and $\mathrm{H}^{-}$. Therefore, it can be assumed that a relatively identical phenomenon also occur at the anode electrode. Further studies are required to confirm this phenomenon.

In order to investigate the dominant carrier-type of the samples after to annealing at $573 \mathrm{~K}$ and $673 \mathrm{~K}$ for $3600 \mathrm{~s}$, the Hall effect measurement test at the room temperature is performed. The result reveals that the dominant carrier-type for the samples is p-type (accepter), i.e., the dominant carrier-type of the samples could be retained after the annealing at $573 \mathrm{~K}$ and $673 \mathrm{~K}$ for $3600 \mathrm{~s}$. The annealing at $573 \mathrm{~K}$ and $673 \mathrm{~K}$ for $3600 \mathrm{~s}$ is suitable for improving the electrical conductivity of $\mathrm{p}-\mathrm{GaN}$, while maintaining the p-type carrier.

\section{Conclusions}

In the present study, Ni thin film $(\sim 20 \mathrm{~nm})$ was uniformly formed on $\mathrm{p}-\mathrm{GaN}$ substrates by radio frequency magnetron sputter deposition method. In order to improve the conductivity and electrical properties of $\mathrm{Mg}$-doped $\mathrm{p}-\mathrm{GaN}$ contact, the enhancement of $\mathrm{H}$ release from $\mathrm{Mg}$-doped $\mathrm{p}-\mathrm{GaN}$ was attempted by applying current flow through the substrates during low temperatures annealing at $573 \mathrm{~K}$ and $673 \mathrm{~K}$. The microstructure and electrical properties after the annealing were then analyzed by transmission electron microscopy observation, direct current conduction tests and Hall effect measurement test. The results reveal that no reactions occur between deposited $\mathrm{Ni}$ film and p-GaN substrate during annealing at $573 \mathrm{~K}$ for $3600 \mathrm{~s}$. The electrical conductivity of $\mathrm{p}-\mathrm{GaN}$ shows higher improvement by applying current flow during annealing at $573 \mathrm{~K}$ and $673 \mathrm{~K}$, compared to annealing without the current flow. To investigate the effect of applying current flow during annealing, the current values of the samples during annealing with and without applying current flow were compared. By applying current flow during annealing, $\mathrm{H}$ ions within $\mathrm{p}-\mathrm{GaN}$ is moved near the interface between $\mathrm{p}-\mathrm{GaN}$ and $\mathrm{Ni}$ film, thus increasing the concentration of $\mathrm{H}$ ions at the interface. $\mathrm{H}$ ions diffuses along the interface to the surface of $\mathrm{GaN}$ and be released to the outside. The $\mathrm{H}$ release from p-GaN can be improved significantly by applying current flow during annealing. By applying this method, the conductivity and electrical properties of $\mathrm{Mg}$-doped $\mathrm{p}$-GaN contact can be improved even at a low annealing temperature. Finally, the Hall effect measurement test reveal that the annealing at $573 \mathrm{~K}$ and $673 \mathrm{~K}$ are suitable for improving the electrical conductivity of $\mathrm{p}-\mathrm{GaN}$ contact, while retaining the p-type carrier.

\section{Acknowledgements}

The authors express their gratitude to Prof. H. Mori and Mr. E. Taguchi for their kind permission and assistance to use facilities in the Research Center for Ultra-High Voltage Electron Microscopy, Osaka University, Japan.

\section{References}

1) M. Asif Khan, Q. Chen, M. S. Shur, B. T. Dermott, J. A. Higgins,J. Burm, W. J. Schaff and L. F. Eastman: GaN based heterostructure for high power devices, Sol. Stat. Electron., 41 (1997) 1555-1559.

2) A.P. Zhang, F. Ren, T. J. Anderson, C. R. Abernathy, R. K. Singh, P. H. Holloway, S. J. Pearton, D. Palmer and G. E. McGuire: HighPower GaN Electronic Devices, Critic. Rev. Solid. Stat. Mater. Sci., 27 (2002) 1-71.

3) K. Motoki, T. Okahisa, S Nakahata, N. Matsumoto, H. Kimura, H. Kasai, K. Takemoto, K. Uematsu, M. Ueno, Y. Kumagai, A. Koukitu and $\mathrm{H}$ Seki: Growth and characterization of freestanding $\mathrm{GaN}$ 
substrates, J. Cryst. Growth, 237-239 (2002) 912-921.

4) Y. Mori, M. Imade, K. Murakami, H. Takazawa, H. Imabayashi, Y. Todoroki, K. Kitamoto, M. Maruyama, M. Yoshimura, Y. Kitaoka and T. Sasaki: Growth of bulk GaN crystal by Na flux method under various conditions, J. Cryst. Growth, 350 (2012) 72-74.

5) I. Akasaki: Key inventions in the history of nitride-based blue LED and LD, J. Cryst. Growth, 300 (2007) 2-10.

6) S. Nakamura, T. Mukai, M. Senoh and N. Iwasa: Thermal Annealing Effects on P-Type Mg-Doped GaN Film, Jpn. J. Appl. Phys., 31 (1992) L139L142.

7) S. Nakamura, M. Senoh and T. Mukai: Highly P-Typed Mg-Doped GaN Films Grown with GaN Buffer Layers, Jpn. J. Appl. Phys., 30 (1991) L1708L1711.

8) H. Amano, M. Kito, K. Hiramatsu and I. Akasaki: P-Type Conduction in Mg-Doped GaN Treated with Low-Energy Electron Beam Irradiation (LEEBI), Jpn. J. Appl. Phys., 28 (1989) L2112L2114.

9) R. Piotrzkowski, E. Litwin-Staszewska, T. Suski and I. Grzegory: Study of dopant activation in bulk GaN: Mg, Physica B, 308310 (2001) 4750 .

10) E. Litwin-Staszewska, T. Suski, R. Piotrzkowski, I. Grzegory, M.Bockowski, J. L. Robert, L. Konczewicz, D. Wasik, E. Kaminska,
D.Cote and B. Clerjaud: Temperature dependence of electrical properties of gallium-nitride bulk single crystals doped with $\mathrm{Mg}$ and their evolution with annealing, J. Appl. Phys., 89 (2001) 79607965.

11) S. J. Pearton, J. C. Zolper, R. J. Shul, and F. Ren: GaN: Processing, defects, and devices, J. Appl. Phys., 86 (1999) 1-78.

12) S. Nakamura, N. Iwasa, M. Senoh, and T. Mukai: Hole Compensation Mechanism of P-Type GaN Films, Jpn. J. Appl. Phys., 31 (1992) 1258-1266.

13) J. Neugebauer and C. G. Van De Walle: Hydrogen in GaN: Novel Aspects of a Common Impurity, Phys. Rev. Lett., 75 (1995) $4452-$ 4455.

14) B. Clerjaud, D. Cote, A. Lebkiri, C. Naud, J. M. Baranowski, K. Pakula, D. Wasik, and T. Suski: Infrared spectroscopy of Mg-H local vibrational mode in GaN with polarized light, Phys. Rev. B, 61 (2000) 8238-8241.

15) S. M. Myers, C. H. Seager, A. F. Wright, B. L. Vaandrager, and J. S. Nelson: Electron-beam dissociation of the $\mathrm{MgH}$ complex in p-type GaN, J. Appl. Phys., 92 (2002) 6630-6635.

16) Aiman bin Mohd Halil, M. Maeda and Y. Takahashi: Effect of $\mathrm{Ti}_{3} \mathrm{SiC}_{2}$ formation on $\mathrm{p}$-type $\mathrm{GaN}$ by vacuum annealing on the contact properties, IOP Conf. Ser.: Mater. Sci. Eng., 61 (2014) 012034. 